\title{
Editorial: The Future of Training in Gerontology in Canada and Other Random Notes
}

In my editorial in the Canadian Journal on Aging/La Revue Canadienne du Vieillissement, vol. 28, no. 1, 2009, I suggested that we might need to adjust our thinking because of the current recession and how it is affecting older Canadians and Canadian Society in general now and will into the future. I did not, however, think I would be writing so soon about how the immediate economic conditions are affecting our universities and colleges and the role of undergraduate training in gerontology.

Over the past 12 months, we have heard about the proposed reorganization of undergraduate programs in gerontology at Canadian universities. It is not my purpose to opine on the specifics of the reasons or decisions. I am in no position to judge the institutions or anyone associated with them, or the underlying reasons for the decisions that have been made or will be made in the future about the role of undergraduate training in gerontology at specific universities.

I would be surprised, however, if any of our university leaders doubt any of the following: that Canadian society and indeed many societies around the world are aging; that between 2025 and 2050, a quarter of Canadian society will be aged 65 and over; and that this will necessitate the training of a formal labour force and an informal population prepared to support the older population when they can no longer live independently. What is disconcerting, if our university leaders and we share these views of the future, is why training in gerontology is seen as a program to be re-organized, downgraded, or cut in these hard times. Should not training in gerontology be a priority, and do we need to make a better case not only for the preservation of current training programs but also for their expansion? Where should training in gerontology take place in our institutions, and should the training be at the undergraduate or graduate level? These are difficult questions to answer, but I am convinced that they need to be discussed and debated in the $C J A / R C V$ and at our annual meetings.

As part of a relationship that dates back to when the Canadian Institutes of Health Research - Institute of Aging (CIHR - IA) first started and the CJA/RCV switched to its current format, I am very pleased to announce that CIHR - IA have worked out an agreement that will see the relationship continue. Beginning with this issue, the CJA/RCV plans to publish a new section, Canadian Institutes of Health Research - Institute of Aging: Profiles. Profiles will normally appear in issues 2 and 4 each year and highlight concerns stemming from research funded by CIHR - IA.

Finally, you will remember that I wrote about the "greening" of the journal in $C J A / R C V$, vol. 27, no. 2, 2008. In joining Cambridge University Press, we have switched our paper to adhere to the standards set by the Forest Stewardship Council (FSC; http:/ / www.fsc. org/). In doing so, the $C J A / R C V$ will be helping to sustain forests around the world.

As always, please contact me at mark.rosenberg@ queensu.ca if you have any thoughts about this editorial or any other aspect of the $C J A / R C V$.

Mark Rosenberg

Editor-in-Chief 